\title{
Inhibitory Effect of African Pumpkin (Momordica balsamina Linn.) Leaf Extract on Copper Corrosion in Acidic Media
}

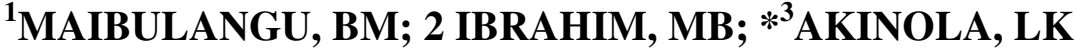

\author{
${ }^{1}$ Department of Chemistry, Aminu Saleh College of Education, Azare, Nigeria \\ ${ }^{2}$ Department of Pure and Industrial Chemistry, Bayero University, Kano, Nigeria \\ ${ }^{3}$ Department of Chemistry, Bauchi State University, Gadau, Nigeria \\ *Corresponding author's e-mail: lukman.akinola@yahoo.com
}

\begin{abstract}
Inhibition of copper corrosion in acidic medium by ethanolic extract of Momordica balsamina leaves was investigated. Findings reveal that the rate of copper corrosion increases with increasing temperature of the medium but decreases as the concentration of the Momordica balsamina extract added to the medium increases. Examination of the surface morphology of copper using Scanning Electron Microscopy (SEM) also reveals that while the surface of copper was seriously damaged in acidic solution in the absence of Momordica balsamina extract, addition of $0.8 \mathrm{mgL}^{-1}$ of the extract significantly protected the copper surface from corrosion. Results obtained from adsorption and thermodynamic studies reveal that the adsorption of the inhibitor on the surface of the copper metal fitted well to both Freundlich $\left(R^{2} \geq 0.948\right)$ and Temkin $\left(R^{2} \geq 0.940\right)$ adsorption models and the low values of activation energies obtained $\left(E_{a} \leq 34.02 \mathrm{kJmol}^{-1}\right)$ indicate that the adsorption of the inhibitor on the copper surface favors the mechanism of physical adsorption. Negative signs of $\Delta G_{a d s}$ obtained in the study suggest that the adsorption of Momordica balsamina on the copper metal is thermodynamically favorable. The data obtained in this study demonstrate that extract of Momordica balsamina leaves probably contains one or more chemical species that protect copper against corrosion through the mechanism of physical adsorption. (C) JASEM

https://dx.doi.org/10.4314/jasem.v21i6.12
\end{abstract}

Keywords: Adsorption, Copper, Corrosion, Inhibitor, Momordica balsamina

\section{Abbreviations and Symbols}

$A=$ area of the copper coupon (in $\mathrm{cm}^{2}$ ); $C=$ concentration of inhibitor; $C_{R}=$ corrosion rate; $E_{a}=$ activation energy; $f=$ a factor of energetic inhomogeneity; $\% I=$ inhibition efficiency; $K_{\text {ads }}=$ equilibrium constant of adsorption; $n=$ a constant for a given adsorbent at a particular temperature; $R=$ universal gas constant $; R^{2}=$ coefficients of determination; $t=$ period of immersion (in hour); $T=$ temperature (in Kelvin); $W_{1}=$ weight loss of copper in the presence of inhibitor (in $g$ ); $W_{2}=$ weight loss of copper in the absence of inhibitor (in $g$ ); $x=a$ measure of adsorbed water molecules; $\theta=$ the degree of surface coverage of the inhibitor; $\Delta W=$ loss in weight of copper; $\Delta G_{a d s}=$ change in free energy of adsorption; $\Delta H_{a d s}=$ change in heat of adsorption; $\Delta S_{a d s}=$ change in entropy of adsorption

Due to their numerous desirable properties, metals and their alloys are widely used in applications ranging from bridge construction, sculpture molding, cutlery making, jewelry production, plumbing, ship building, and electrical power generation, transmission and distribution. However, one of the major problems with the use of metals and their alloys in technological applications is corrosion and its attendant health, environmental and economic implications. Corrosion is an oxidative or chemical destruction of materials (mostly metals and alloys) due to the interaction of the materials with their environment (Bagotsky, 2006). General pathways for electrochemical corrosion of metals in several media in the presence and absence of oxygen are well documented in the literature (Stansbury and Buchanan, 2000).

Contrary to widespread belief that copper is resistant to corrosion, scientific literature abounds with sufficient evidence to show that copper and its alloys are susceptible to corrosion under suitable environmental conditions (Apted et al, 2009). It can also be demonstrated using thermodynamic argument that copper is liable to corrosion under suitable conditions since the fundamental driving force for all corrosion is the lowering of Gibbs free-energy. For instance, the pathway for oxidative destruction of copper in acidic medium in the presence of oxygen is shown in Scheme 1, and the value of Gibbs freeenergy change calculated for this redox reaction $(\Delta G$ $=-344.26 \mathrm{KJ}$ ) indicates that the corrosion process is spontaneous since the sign of $\Delta \mathrm{G}$ obtained is negative. This calculated $\Delta \mathrm{G}$ value indicates that, in the presence of oxygen, corrosion of copper in acidic medium is thermodynamically favorable.

Although corrosion is an inevitable natural process since all metals have strong tendencies to return to their low energy states, the rate of oxidative conversion of metals to their low energy states can be controlled by several methods. For instance, rate of 
metal corrosion can be slowed down by direct and electrochemical applications of surface coatings (Ohtsuka, 2012; Nassif and Ghayad, 2013), use of corrosion inhibitors (Antonijevic and Petrovic, 2008; Dar, 2011; Kesavan et al, 2012), and cathodic protection (Jayapalan et al, 2014). Among the various methods available for corrosion control and protection, the use of corrosion inhibitors is the most popular because the approach is cheap and easy to operate (Dar, 2011; Singh et al, 2013). However, survey of literature shows that some corrosion inhibitors have undesirable health and environmental implications due to their toxicity (Singh et al, 2012). Globally, this has prompted the search for alternative inexpensive, eco-friendly and renewable corrosion inhibitors from various plant species (Rajalakshmi et al, 2012). It is against this background that the current research work set out to investigate the inhibitory potential of Momordica balsamina leaf extract on copper corrosion in acidic medium.

$$
\begin{array}{lc}
2 \mathrm{Cu} \rightarrow 2 \mathrm{Cu}^{2+}+4 e^{-} \text {(anodic reaction) } & E^{0}=-0.337 \mathrm{~V} \\
\mathrm{O}_{2}+4 \mathrm{H}^{+}+4 e^{-} \rightarrow 2 \mathrm{H}_{2} \mathrm{O} \text { (cathodic reaction) } & E^{0}=+1.229 \mathrm{~V} \\
2 \mathrm{Cu}+\mathrm{O}_{2}+4 \mathrm{H}^{+} \rightarrow 2 \mathrm{Cu}^{2+}+2 \mathrm{H}_{2} \mathrm{O} \text { (overall reaction) } & E_{\text {cell }}^{0}=+0.892 \mathrm{~V}
\end{array}
$$

Scheme 1: Electrochemical corrosion of copper in acidic medium in the presence of oxygen

\section{MATERIALS AND METHODS}

Preparation of Copper Coupons: Copper metal was mechanically pressed and cut into $1.0 \times 0.5$ inch coupons. Each coupon was $1.32 \mathrm{~mm}$ in thickness. The copper coupons were degreased in acetone, dried in ambient air, and stored in moisture-free desiccators before use in subsequent corrosion studies

Preparation of Acidic Solution: Acidic solution containing $0.8 \mathrm{moldm}^{-3} \mathrm{HCl}$ was prepared by dissolving $70.80 \mathrm{~cm}^{3}$ of concentrated $\mathrm{HCl}$ in distilled water and diluting the resulting solution to volume in 1 $\mathrm{dm}^{3}$ volumetric flask (Mendham et al, 2000).

Preparation of Inhibitor: Leaves of Mormordica balsamina (African Pumpkin) were obtained from a farm in Azare, Bauchi State, Nigeria. The leaves were dried under shade for one week, pulverized using mortar and pestle, and then sieved to separate the smaller particles from the larger ones. Thereafter, $250 \mathrm{~g}$ of the powdered plant material was weighed and soaked in $1 \mathrm{dm}^{3}$ of ethanol for two weeks with intermittent stirring. The solution obtained was filtered using Whatman number 1 filter paper. The extracted secondary metabolites in the filtrate was separated from the solvent using a rotary evaporator at $40{ }^{\circ} \mathrm{C}$ and the resulting thick green jelly extract obtained was allowed to dry under laboratory condition in one week.

Measurement of Corrosion Rate: Several cleaned copper coupons were weighed before the commencement of the experiments using electronic digital weighing balance. These previously weighed copper coupons were tied with threads, suspended and immersed in $100 \mathrm{~cm}^{3}$ of test solutions containing 0.8 mold $^{-3} \mathrm{HCl}$ with different concentrations of the inhibitor $\left(0.2,0.4,0.6\right.$ and $\left.0.8 \mathrm{mgL}^{-1}\right)$. A blank solution containing $100 \mathrm{~cm}^{3}$ of $0.8 \operatorname{moldm}^{-3} \mathrm{HCl}$ without the inhibitor was used as the control experiment. The beakers containing the blank and test solutions were covered with aluminum foil and placed in a thermostatic water baths at temperatures of 303 , 313,323 and $333 \mathrm{~K}$. Each coupon was retrieved from the blank and test solutions at interval of 1 hour for 5 hours. The coupons were degreased in ethanol using brush, air-dried after dipping in acetone and then reweighed. Triplicate experiments were performed in each set of the test and the mean values of the weight loss are reported. The difference in weight for a period of 5 hours was taken as the total weight loss. From the average weight loss results, the inhibition efficiency $(\% \mathrm{I})$ of the inhibitor, the degree of surface coverage $(\theta)$ and the corrosion rate were calculated using equations 1,2 and 3 . Where $\mathrm{W}_{1}$ and $\mathrm{W}_{2}$ are the weight losses $(\mathrm{g})$ for copper in the presence and absence of the inhibitor, $\Theta$ is the degree of surface coverage of the inhibitor, $\Delta \mathrm{W}$ $=\mathrm{W}_{2}-\mathrm{W}_{1}$, $\mathrm{A}$ is the area of the copper coupon (in $\mathrm{cm}^{3}$ ), $\mathrm{t}$ is the period of immersion (in hour) and $\Delta \mathrm{W}$ is the weight loss of copper after 1, 2, 3, 4, and 5 hours.

$$
\begin{gathered}
\% I=\left(1-W_{1} / W_{2}\right) \times 100 \% \\
\theta=1-W_{1} / W_{2} \\
C_{R}=\Delta W / A t
\end{gathered}
$$

Scanning Electron Microscopic (SEM) Study: The surface morphology of the copper before and after corrosion was studied using a JSM- 5600 LV Scanning electron microscope (JEOL, Tokyo, Japan). The sample was mounted on a metal stub and the images were taken at an accelerating voltage of $10 \mathrm{kV}$.

\section{RESULTS AND DISCUSSION}

Effects of Temperature and Inhibitor concentration on Corrosion Rate: Figure 1 shows the variations of corrosion rates of copper in acidic medium as a function of temperature and inhibitor concentration. As 
shown in Figure 1, the corrosion rate of copper metal in the presence and absence of the inhibitor increases as the temperature of the medium increases. Figure 1 also shows that the corrosion rate of copper in the presence of the inhibitor is lower than the corrosion rate in the absence of the inhibitor at all temperatures, and the decrease in corrosion rate becomes more pronounced as the concentration of inhibitor increases. This indicates that the extract of Momordica balsamina produces an inhibitory effect on the rate of corrosion of copper metal in acidic medium. The results presented above are in agreement with other findings reported in the literature (Sulay et al, 2015). These findings are in conformity with the theory of reaction rate, since rates of most physical and chemical processes generally increases with increase in temperature according to Arrhenius theory of reaction rate (Al-Haj-Ali et al, 2014).

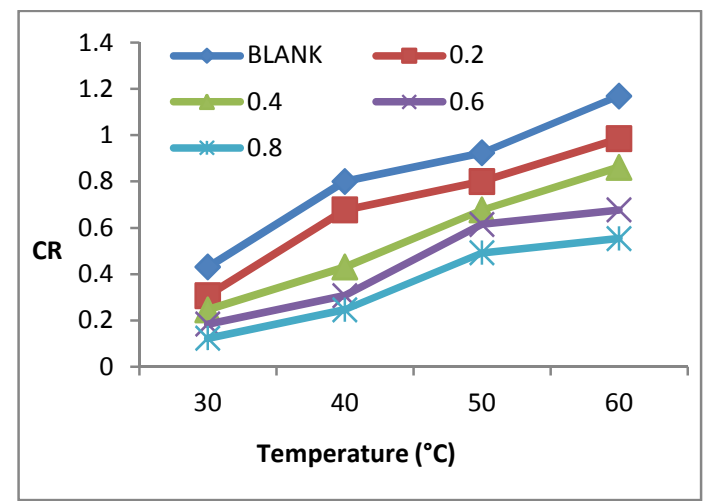

Fig 1: Variation of corrosion rate in acidic medium with temperature in the absence and presence of inhibitor

Effects of Temperature and Inhibitor concentration on Inhibition Efficiency: The variations in inhibition efficiency as a function of inhibitor concentration and temperature in acidic medium is presented in Table 1.

Table 1: Variation of inhibition efficiency in acidic medium with inhibition concentration at various temperatures

\begin{tabular}{ccccc}
\hline $\begin{array}{c}\text { Inhibitor } \\
\text { concentration }\end{array}$ & \multicolumn{4}{c}{$\begin{array}{c}\text { Inhibition efficiency (\%) in acidic } \\
\text { medium }\end{array}$} \\
\cline { 2 - 5 } & $30{ }^{\circ} \mathrm{C}$ & $40{ }^{\circ} \mathrm{C}$ & $50{ }^{\circ} \mathrm{C}$ & $60{ }^{\circ} \mathrm{C}$ \\
$\mathbf{0 . 2}$ & 28.57 & 15.38 & 13.33 & 15.79 \\
$\mathbf{0 . 4}$ & 42.86 & 46.15 & 26.67 & 26.32 \\
$\mathbf{0 . 6}$ & 57.14 & 61.54 & 33.33 & 42.11 \\
$\mathbf{0 . 8}$ & 71.43 & 69.23 & 46.67 & 52.63 \\
\hline
\end{tabular}

As shown in the Table, the inhibition efficiency increases as the concentration of the inhibitor increases at all temperatures. However, for a given inhibitor concentration, inhibition efficiency decreases as the temperature increases. In acidic medium, a maximum inhibition efficiency of $71.43 \%$ was observed at $30{ }^{\circ} \mathrm{C}$ using $0.8 \mathrm{~g} / \mathrm{L}$ of inhibitor. The result presented here is in conformity with other findings reported in the literature (Umoren and Ebenson, 2008). This can be explained if due consideration is given to the fact that, at higher temperature, the surface coverage of the copper metal by the inhibitor becomes less as a result of losses due to desorption (Al-Haj-Ali et al, 2014).

Adsorption Isotherm and Thermodynamic Studies: Data obtained for the adsorption of Momordica balsamina onto the surface of copper metal were fitted to the linear forms of equations describing Langmuir adsorption isotherm (equation 4), Freundlich adsorption isotherm (equation 5), Flory-Huggins adsorption isotherm (equation 6), and Temkin adsorption isotherm (equation 7). The adsorption parameters and the coefficients of determination $\left(R^{2}\right)$ derived from these adsorption isotherms at various temperatures are summarized in Tables 2, 3, 4 and 5 for Langmuir, Freundlich, FloryHuggins, and Temkin isotherms respectively. As shown in these Tables, the adsorption fitted well to both Freundlich adsorption isotherm $\left(\mathrm{R}^{2} \geq 0.940\right)$ and Temkin adsorption isotherm $\left(\mathrm{R}^{2} \geq 0.948\right)$ at all temperatures. Tables 3 and 5 also show that the values of $K_{a d s}$ obtained for Freundlich adsorption isotherm ranged from $0.557 \mathrm{mgg}^{-1}$ at $50{ }^{\circ} \mathrm{C}$ to $1.028 \mathrm{mgg}^{-1}$ at $40{ }^{\circ} \mathrm{C}$ while the values of $K_{a d s}$ obtained for Temkin adsorption isotherm ranged from $7.656 \mathrm{mgg}^{-1}$ at $40{ }^{\circ} \mathrm{C}$ to $11.96 \mathrm{mgg}^{-1}$ at $30^{\circ} \mathrm{C}$.

Plots of $\log C_{R}$ against $1 / T$ were plotted at various concentrations of the inhibitors using Arrhenius equation (equation 8) and values of activation energies and pre-exponential factors obtained from these plots are presented in Table 6. As shown in Table 6, values of activation energies ranging from 25.96 to 34.02 $\mathrm{kJmol}^{-1}$ were obtained for experiments conducted in various concentrations of acid. These findings suggest that the mechanism of Momordica balsamina adsorption onto the surface of copper metal involves physical adsorption since value of activation energy lower than the threshold value of $80 \mathrm{kJmol}^{-1}$ is indicative of physical adsorption mechanism (Eddy and Ebenso, 2010). Using the values of $K_{a d s}$ (the equilibrium constants) obtained from Temkin adsorption model, values of $\Delta G_{a d s}$ (change in free energy of adsorption) were calculated using equation 9. Also, $\Delta H_{a d s}$ (change in heat of adsorption) and $\Delta S_{a d s}$ (change in entropy of adsorption) were calculated using equations 10 and 11 respectively. The calculated values of $\Delta G_{a d s}, \Delta H_{a d s}$ and $\Delta S_{a d s}$ obtained for experiments carried out in acidic solution at various temperatures are presented in Tables 7. As shown in Table 7, the negative values of $\Delta G_{a d s}$ indicate that the adsorption of Momordica balsamina onto the surface of copper metal is a spontaneous process (Eddy and Ebenso, 2010). 
Also shown in Table 7 are the values of $\Delta H_{a d s}$ and $\Delta S_{a d s}$ for the adsorption of Momordica balsamina onto the surface of copper metal at various temperatures. The negative value of $\Delta H_{a d s}$ at each temperature is an indication that the adsorption of Momordica balsamina onto the surface of copper metal is an exothermic process and the positive value of $\Delta S_{a d s}$ at each temperature is an indication that there is an increase in degree of freedom of the system (Sharma et al, 2010).

$$
\begin{aligned}
& C / \theta=1 / K_{a d s}+C \\
& \log \theta=\log K_{a d s}+n \log C \\
& \log \theta / C=\log K+x \log (1-\theta) \\
& \theta=1 / f \ln K_{a d s}+1 / f \ln C \\
& \ln C_{R}=\ln A-E_{a} / R T \\
& \Delta G_{a d s}=-2.303 R T \log \left(55.5 K_{a d s}\right)(9) \\
& \Delta H_{a d s}=E_{a}-R T \\
& \Delta G_{a d s}=\Delta H_{a d s}-T \Delta S_{a d s}
\end{aligned}
$$

Table 2: Langmuir isotherm constants and coefficients of determination for corrosion inhibition of copper in acidic medium

\begin{tabular}{llcc}
\hline Temperature $^{\circ} \mathbf{C}$ & $\boldsymbol{K}_{\text {ads }}(\mathbf{m g} / \mathbf{g})$ & $\boldsymbol{R}_{\boldsymbol{L}}$ & $\boldsymbol{R}^{\mathbf{2}}$ \\
\hline $\mathbf{3 0}$ & 1.650 & 0.752 & 0.932 \\
$\mathbf{4 0}$ & 2.128 & 0.701 & 0.047 \\
$\mathbf{5 0}$ & 1.572 & 0.761 & 0.636 \\
$\mathbf{6 0}$ & 1.942 & 0.721 & 0.515 \\
\hline
\end{tabular}

Table 3: Freundlich isotherm constants and coefficients of determination for corrosion inhibition of copper in acidic medium

\begin{tabular}{lllc}
\hline Temperature ${ }^{\circ} \mathrm{C}$ & $K_{\text {ads }}(\mathrm{mg} / \mathrm{g})$ & $\mathrm{N}$ & $R^{2}$ \\
\hline 30 & 0.809 & 0.656 & 0.995 \\
40 & 1.028 & 1.107 & 0.940 \\
50 & 0.557 & 0.876 & 0.988 \\
60 & 0.638 & 0.884 & 0.991 \\
\hline
\end{tabular}

Table 4: Flory-Huggins isotherm constants and coefficients of determination for corrosion inhibition of copper in acidic medium

\begin{tabular}{lllc}
\hline Temperature $^{\circ} \mathbf{C}$ & $\boldsymbol{K}_{\text {ads }}(\mathbf{m g} / \mathbf{g})$ & $\mathbf{X}$ & $\boldsymbol{R}^{\mathbf{2}}$ \\
\hline $\mathbf{3 0}$ & 1.520 & 0.473 & 0.805 \\
$\mathbf{4 0}$ & 0.861 & -0.125 & 0.094 \\
$\mathbf{5 0}$ & 0.697 & 0.328 & 0.507 \\
$\mathbf{6 0}$ & 0.771 & 0.218 & 0.420 \\
\hline
\end{tabular}

Table 5: Temkin isotherm constants and coefficients of determination for corrosion inhibition of copper in acidic medium

\begin{tabular}{lllc}
\hline Temperature ${ }^{\circ} \mathrm{C}$ & $K_{\text {ads }}(\mathrm{mg} / \mathrm{g})$ & $\mathrm{f}$ & $R^{2}$ \\
\hline 30 & 11.98 & 3.333 & 0.960 \\
40 & 7.656 & 2.538 & 0.992 \\
50 & 8.556 & 4.444 & 0.954 \\
60 & 8.212 & 3.774 & 0.948 \\
\hline
\end{tabular}

Table 6: Arrhenius parameters for the temperature dependence of corrosion rate at different concentrations of inhibitor in acidic medium

\begin{tabular}{lll}
\hline$\left[\boldsymbol{H}^{+}\right]\left(\right.$moldm $\left.^{-3}\right)$ & $\boldsymbol{E}_{\boldsymbol{a}}\left(\mathrm{kJmol}^{\mathbf{- 1}}\right)$ & $\mathbf{A}$ \\
\hline $\mathbf{0 . 2}$ & 34.02 & 15.39 \\
$\mathbf{0 . 4}$ & 25.96 & 0.946 \\
$\mathbf{0 . 6}$ & 26.26 & 1.317 \\
$\mathbf{0 . 8}$ & 26.54 & 1.815 \\
\hline
\end{tabular}

Table 7: Thermodynamic parameters for the adsorption of the inhibitor on copper metal in acidic medium

\begin{tabular}{lllll}
\hline $\begin{array}{l}\mathbf{T} \\
\left({ }^{\circ} \mathbf{C}\right)\end{array}$ & $\begin{array}{l}\mathbf{K}_{\text {ads }} \\
(\mathbf{m g} / \mathbf{L})\end{array}$ & $\begin{array}{l}\Delta \mathbf{G}_{\text {ads }} \\
(\mathbf{k J} / \mathbf{m o l})\end{array}$ & $\begin{array}{l}\Delta \mathbf{H}_{\text {ads }} \\
(\mathbf{k J} / \mathbf{m o l})\end{array}$ & $\begin{array}{l}\Delta \mathbf{S}_{\text {ads }} \\
(\mathbf{J} / \mathbf{m o l} . \mathbf{K})\end{array}$ \\
\hline $\mathbf{3 0}$ & 11.98 & -16.376 & -2.493 & +45.821 \\
$\mathbf{4 0}$ & 7.656 & -15.752 & -2.576 & +42.095 \\
$\mathbf{5 0}$ & 8.556 & -16.553 & -2.659 & +43.017 \\
$\mathbf{6 0}$ & 8.212 & -16.952 & -2.742 & +42.673 \\
\hline
\end{tabular}

Studies on Surface Morphology: The surface morphologies of copper before immersing in acidic solution, 5 hours after immersing in acidic solution in the absence of inhibitor, and 5 hours after immersing in acidic solution in the presence of $0.8 \mathrm{mgL}^{-1}$ of inhibitor were studied, and the results obtained were presented as scanning electron micrographs in Figures 2, 3 and 4 respectively. Comparison of Figures 2 and 3 indicates that the surface of copper is seriously damaged by corrosion in the test solution in the absence of the inhibitor. However, on comparing Figures 2 and 4 , it can be seen that the corroding effect of the test solution is drastically minimized probably due to the formation of protective coverage on the surface of the copper coupon by the inhibitor. The result obtained from the scanning electron micrographs is consistent with the fact that Momordica balsamina contains compounds that inhibited the corrosion of copper in acidic medium through the mechanism of adsorption. The inhibitor tends to form adsorbed layers on the surface of the metal and protect the metal against corrosion

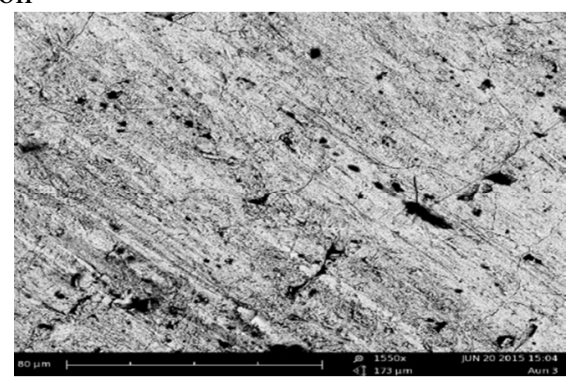

Fig 2: scanning electron microgram of copper before inserting in acidic solution

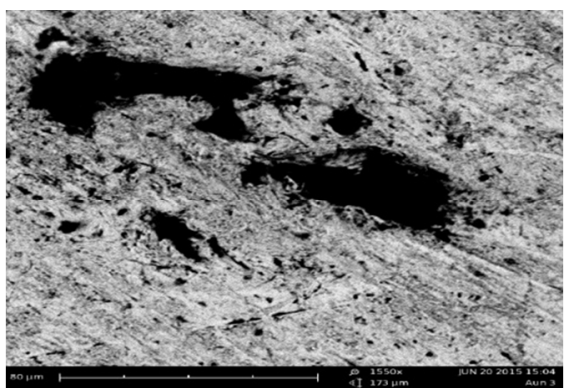

Fig 3: Scanning electron microgram of copper in 0.8 moldm ${ }^{-3} \mathrm{HCl}$ without inhibitor 


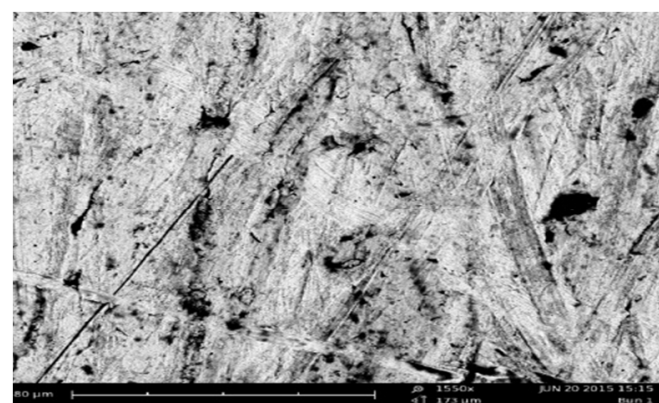

Fig 4: Scanning electron microgram of copper in 0.8 moldm $^{-3} \mathrm{HCl}$ containing inhibitor

Conclusion: The search for alternative source of corrosion inhibitors from locally available materials provided the motivation for conducting this research work. Ethanolic extract of Momordica balsamina leaves was investigated for its potential in protecting copper against corrosion in acidic medium. All the structural, kinetic and thermodynamic data generated from the research work demonstrate that Momordica balsamina leaf extract probably contains one or more chemical species that enable it to serve as an alternative corrosion inhibitor for copper in acidic medium.

\section{REFERENCES}

Al-haj-Ali, AM.; Jarrah, NA; Mu'azu, ND; Rihan, RO (2014). Thermodynamics and kinetics of inhibition of aluminum in hydrochloric acid by date palm leaf extract. Journal of Applied Science and Environmental Management, 18(3): 543 - 551.

Antonijevic, MM; Petrovic, MB (2008). Copper corrosion inhibitors: a review. International Journal of Electrochemical Science, 3: 1-28.

Apted, MJ; Bennett, DG; Saario, T (2009). A review of evidence for corrosion of copper by water. A report of Swedish Radiation Safety Authority, available at www.stralsakerhetsmyndigheten.se

Bagotsky, VS (2006). Fundamentals of Electrochemistry, John Wiley \& Sons Inc, New Jersey, pp. 379 - 386.

Dar, MA (2011). A review: plant extracts and oils as corrosion inhibitors in aggressive media. Industrial Lubrication and Tribology, 63(4): 227 - 233.

Eddy, NO; Ebenso, EE (2010). Adsorption and quantum chemical studies on cloxacillin and halides for the corrosion of mild steel in acidic medium. International Journal of Electrochemical Science, 5: $731-750$.

Jayapalan, G; Agnihotri, G; Deshpande, DM (2014). Cathodic protection of pipeline using distributed control system. Chinese Journal of Engineering, Article ID 681908.

Kesavan, D; Gopiraman, M; Sulochana, N (2012). Green inhibitors for corrosion of metals: a review. Chemical Science Review and Letters, 1(1): $1-8$.

Mendham, J; Denney, RC; Barnes, JD; Thomas, MJK (2000). Vogel's textbook of quantitative chemical analysis, 6th ed., Prentice Hall, England, p. 315.

Nassif, N; Ghayad, I (2013). Corrosion protection and surface treatment of magnesium alloys used for orthopedic applications. Advances in Materials Science and Engineering, Article ID 532896.

Ohtsuka, T (2012). Corrosion protection of steels by conducting polymer coating. International Journal of Corrosion, Article ID 915090.

Rajalakshmi, R; Prithiba, A; Leelavathi, S (2012). An overview of emerging scenario in the frontiers of ecofriendly corrosion inhibitors of plant origin for mild steel. Journal of Chemica Acta, 1: 6 - 13.

Sharma, SK; Mudhoo, A; Gargi, J; Sharma, J (2010). Corrosion inhibition and adsorption properties of Azadirachta indica mature leaves extract as green inhibitor for mild steel in $\mathrm{HNO}_{3}$. Green Chemistry Letters and Reviews, 3(1): 7 - 15.

Singh, A; Ebenso, EE; Quraishi, MA (2012). Corrosion inhibition of carbon steel in $\mathrm{HCl}$ solution by some plant extracts. International Journal of Corrosion, Article ID 897430.

Singh, A; Lin, Y; Liu, W; Ebenson, EE; Pan, J (2013). Extract of Momordica charantia (karela) seeds as corrosion inhibitor for P110SS steel in $\mathrm{CO}_{2}$ saturated $3.5 \% \mathrm{NaCl}$ solution. International Journal of Electrochemical Science, 8: 12884 - 12893.

Stansbury, EE; Buchanan, RA (2000). Fundamentals of Electrochemical Corrosion, ASM International, United States of America.

Sulay, KZ; Victor, AU; Obed, B; Olufemi, AO (2015). Kinetic and thermodynamic study of inhibition potentials by ethoxyethane Extracts of Cochlospermum tinctorium for the oxoacid corrosion of mild steel. International Journal of Materials and Chemistry, 5(3): $64-76$.

Umoren, SA; Ebenso, EE (2008). Studies of anti-corrosive effect of Raphia hiikeri exudates gum-halide mixtures for aluminium corrosion in acidic medium. Pigment and Resin Technology, 37(3): 173-182. 